\title{
Brief Discussion on Historical Evolution of Sichuan Opera Tune Music
}

\author{
Shengdong Yue ${ }^{1}$ \\ ${ }^{1}$ Chengdu Normal University Academy Of Music, Chengdu, Sichuan,611130
}

Key words: Sichuan opera, tune music, high-pitched tune, evolution

\begin{abstract}
In this paper, taking high-pitched tune, the most representative and most development-impeccable in five tunes of Sichuan Opera as one example, by analyzing relevant historical facts and materials to take brief comb and discourse for Sichuan opera tune including Kun Opera, High-pitched Tune, Huur, Tanxi, Lantern tune. Actually, the Sichuan Opera with modern sense forms in early $20^{\text {th }}$ century and the reason of the formation is the urbanization and commercialization development tendency of local opera art, which promotes different tunes' merging spread in various districts of Sichuan and then after hundreds of intercourse performance, Sichuan opera implements its localization which forces the formation of 'Five in One Tune' modern Sichuan opera.
\end{abstract}

\section{Introduction}

Sichuan opera, as one of China Four Big Operas includes Kun Opera, High-pitched Tune, Huur, Tanxi, Lantern tune and speakers from educational circles think that these five tunes, except for lantern tune originating from native, the others are all the result of the combination of local dialect, folk music, folk tradition and fold customs with external tunes after coming into Sichuan and the combination evolution. After further integration and interaction of derived tunes with Sichuan characteristics, Sichuan Opera---Sichuan local opera with 'Five in One Tune' comes into being.

The total constitution of Sichuan tune music is made up with two parts: singing and accompaniment music and the five tunes respectively belong to five tune systems of traditional opera: Kun Opera, High-Pitched Tune, Pihuang Tune, Bangzi Tune and folk song and dance and the accompaniment music is made up with percussion music and orchestral music. The difference between Sichuan opera and other traditional Chinese operas mainly shows in high-pitched tune and gong and drum, among which the most characteristic is vocal accompany(1), beating (in percussion music) and singing, besides, you can know that gong and drum belongs to Sichuan opera once you hear it. Gong and drum music is the long-time popular folk percussion music in Sichuan and its adjacent area, and it has typical and full-bodied local color. It is infrequent for opera to express dramatic plot and music rhythm by using gongs and drums like Sichuan opera in China traditional operas art system.

There is many records of Sichuan opera art in history and it originates from Han dynasty, being popular in Tang dynasty withe saying 'Sichuan opera popular in the world', and record of Sichuan miscellaneous drama in Song dynasty, Sichuan opera and Sichuan tune in Ming dynasty, which seems explaining that Sichuan folk opera art has more outstanding Sichuan style and Sichuan charm all long. In Qianlong period, Sichuan actors Wei Changsheng, Chen Yinguan etc are famous by their works Warm Someone by Fire and Floor Rolling with typical Sichuan characteristics in Peking, which is widely known in the history with the record of Qin opera overwhelming Peking opera. Actually, Sichuan opera was born in the period of 'Local Opera' flourish in emperor Yongzheng and 
Qianlong period of Qing dynasty, because of the event of Immigrant Coming into Sichuan, the situation of various operas coexistence appears and then after long-time evolution, the opera with obvious Sichuan characteristic forms finally.

The existing document literature indicate that most of Kun Opera, High-pitched Tune, Huur, Tanxi, Lantern tune in Chuan opera are originate from other provinces. After the introduction of Kunshan tune in Jiangsu province, Yiyang tune in Jiangxi province, Pihuang tune in Hubei province and Qin tune in Shanxi province to Sichuan province, in order to adapt to Sichuan people's appreciation custom and aesthetic taste in spread course, these tunes begin to mix with Sichuan language and local music, which promotes the formation of new tune with local typical characteristics and different to original tunes. At the same time, in the aspects of language, structure and expression methods, relevant changes and development happen in certain degree, which also promotes art development and changes, especially for the changes of performance procedure skills in rhythm and melody. So after the period of emperor Jiaqing and Daoguang in Qing dynasty, although the singing of opera folk troupes which only sing single-tune operas, such as, Kun opera folk troupe, Huqin folk troupe, carrom folk troupe, is not titled with Sichuan opera, it becomes Sichuan-style opera tune gradually. The situation of various tunes coexistence in Sichuan district and great life pressure on actors promotes the joint performance of single-tune singing folk troupe and another tune singing folk troupe or introduce other actors and operas with different tunes. Gradually, the increase of folk troupe with at least two tunes promote the permeation and absorption of various tune, especially for the mix of gong-drum and performance, which confluence situation is called 'Two Mix folk troupe 'or 'Three Mix folk troupe ', corresponding to this, singing by using several different tunes in one opera is called 'Two in One Pot' or 'Three in One Pot'.

After First Opium War, China's feudal agricultural natural economy began to disintegrate and the long-time scattered traditional opera art in country began to coming into city to seek new development. In 1907, Zhou Shanpei of Sichuan Police General Office advocated to set up Opera Reform Community with the tenet of 'Improving Opera, Assisting Social Education ' in the influence of 'Opera Reform Movement' in late Qing dynasty, which promoted opera come into a new unprecedented situation of official organization and leading, great attention on opera by ruling authorities paid, intelligentsia's positive participation, actors' advancement and endeavor and the audience's enthusiastic reflection. This community became one platform of integrating various social forces to improve opera and assist social education, which embodies in the scenario writing by progressive intellectuals, such as Huang Ji'an, Zhaoxi etc and demonstration performance by famous actors, such as Kang Zhilin, Zhou Mingchao etc, besides, some fixed places, such as 'Yuelai Tea Garden' are constructed as the performance place.

In 1912, opera folk troupes in Chengdu, Cuihua folk troupe, Caihua troupe, Yanle troupe, Changle troupe,Binle troupe, Guichun troupe, Taihong troupe and Shuyi troupe merged to form one entertainer association 'Three Celebration Troupe', which attracted social distinguished personages in various professions and divas from entertainment profession and it is the first opera folk group totally constructed and administrated by opera artists in history. In 30 years after the establishment of 'Three Celebration Troupe', intentional improvement and reform have been taken on management system, assignment system, opera creation and art style etc, and it also combines various tunes of Kun Tune, High-pitched Tune, Huqin, Carrom, Lantern Tune etc, which not only sets a good example for other operas in Sichuan, but also lays foundation for the development of modern Sichuan opera. In the period before and after May Fourth Movement, because the style of operas in Sichuan gradually fixed, additionally famous actors show their faces to people and famous masterpieces of celebrities comes to the ground, so people regard conventionally Sichuan opera as 
one relatively independent opera with various tunes in it, which is also the signal of differentiating it from other operas in Chinese opera art.

High-pitched tune is the most impeccable and typical-developing tune with a long history, which ranks only second to local protogenetic 'Lanten Opera', so we can feel the development and evolution of Sichuan tune from the rheological process of high-pitched tune. Most opera history articles record that Sichuan high-pitched tune originates from Jiangxi Yiyang tune, however there is no exact supporting material for that. Li Diaoyuan records the origination of high-pitched tune in his Opera in Rainy Country that, high-pitched tune originates from Yiyang tune and the singing melodies all belong to north tune. Besides, another appellation of high-pitched tune is Yang Tune, and actually the character 'Yang' is the shifted sound of character 'Yi'. (2) However, according to the textual research of Deng Yunjia, there is no any document record about the introduction of Yiyang tune to Sichuan. Deng Yunjia thinks that, for Sichuan high-pitched tune, Li Diaoyuan calling it 'Yang tune', and thinking Yang being the shifted sound of Yi, it may indicates that Sichuan high-pitched originates from Yang tune. Bang (tune), Beating(percussion music) and singing of Sichuan high-pitched tune are not introduced or input, and they originate from Sichuan local folk ditties 'Bamboo song' and 'Yang song', because Sichuan has the condition for producing this type of art, besides, Sichuan high-pitched tune and Jiangxi Yiyang tune in Ming dynasty are the brother-tune, which is the outcome after the succession and development of North opera in the Song and Yuan dynasties.

Actually, may tunes of opera evolved and derived from Yiyang tune in Ming dynasty all belong to high-pitched tune system, however, the difference between Suchuan high-pitched tune and Yiyang tune is the evolution process and applied range. Statistics have been made by Ye Dejun that vocal accompany conditions of existing three old north operas is: the quantity of vocal accompany in Story of Official Family's Children is three,the quantity of vocal accompany in Xiao Sun tu is fourty-five, the quantity of vocal accompany in Number One Scholar Zhang Xie is one hundred and sixty-nine. However, these vocal accompany belong to tail vocal accompany basically, which often repeat actor's last sentence or half of last sentence, even one or two words. Sichuan high-pitched tune not only has the form of tail vocal accompany, but also has large number of head vocal accompany and belly vocal accompany, besides, it often has the combined application situation of these three vocal accompany. Deng Yunjia has taken general statistics for vocal accompany situation of Sichuan High-pitched Qupai, the result shows that, almost 90\% of Sichuan High-pitched Qupai have head vocal accompany, and the situation of more vocal accompany less singing and total vocal accompany no singing is the character that Yiyang tune opera does not have or partly have. (3)

Because the traditional high-pitched tune has the character of 'No decorating of orchestra, only gong-drum around, one person starting with many vocal accompany', and it is one 'Only Singing 'performance form of one singing with many other people’s help. The libretto is colloquial and do not need accompaniment music, besides, it is easy for vocal accompany and gong-drum to create atmosphere, so it is popular in common people and widespread in Sichuan district. In the long period of high-pitched spread in Sichuan, it absorbs the musical element of Kun tune and Lantern tune, gradually combines with Sichuan dialect and folk music and enriches itself expressive force and take changes in Qupai, type of metre, melody, tune etc, which has unique style in opera high-pitched system. After 1949, Sichuan opera began to arrange professional vocal accompany personnel with female vocal accompany as primary and the forms include, collar cavity, closed cavity, simultaneous cavity, mixed cavity etc, besides, in the course, the cooperation forms of the performance of singing tune, vocal accompany, gong-drum are various. From the beginning of $1950^{\text {th }}$, because of the positive intervention of 'new music worker', the traditional Qupai of Sichuan 
high-pitched is also divided systematicly into several levels: 'Duanzhenghao’'New Shuiling”'River Osmanthus ”Fragrant Luodai’'Red Cotton Coat”Reciting”Suosuo Gang' in order to distinguish different feelings and thought in different roles.

Totally, there are three sayings about the origin of Sichuan opera, that is, 'Native saying "'External saying 'Mixed saying .'The people holding the theory of 'Native saying', mostly take the Sichuan Zaju mentioned in Teacher Ma's Moon Play in Xitang, Baizhang, Nanquan by eminent monk Shi Daolong and the article Fine Book Chen Dashen Green Autumn-Sichuan Opera by Chenduo in Ming dynasty as evidence to demonstrate the Sichuan opera origin, even trace its origin to 'Ba Yu Dance'in Han dynasty. The people holding the theory of 'External saying' take the records in generated history about external province music actors' performance in Sichuan and the Sichuan opera groups' performance in external province as evidence, they think that the opera tunes from external provinces played decisive funcion in the formation of Sichuan opera. The writer of this paper endorses the 'Mixed saying', which put forward the thought on the basis of 'Native saying "External saying 'that Large number of immigrants from external provinces coming into Sichuan promoted the 'Mixed stream'of Kun tune, high-pitched tune, Huqin, carrom and lantern tune and after the gradual adapting and mix of various tunes with Sichuan dialect and folk tunes and hundred of years' joint performance, the external tunes achieved the localization, furthermore, the modern Sichuan opera with 'Five in One'character has its complete form in the leading of current political situation and official promoting in early 20th century.

\section{Acknowledgements}

Fund: Ministry of Education Humanities-Social Science Study Youth Fund Project 'Formation, Development and Evolution Study of Modern Sichuan Opera', Project No. : 15YJC760123, Breeding project of Chengdu Normal University 'Formation, Development and Evolution Study of Modern Sichuan Opera’, Project No. : CS14SD04. 